\title{
Caractérisation de la flore dans les espaces de maraîchage : cas d'une parcelle de menthe en zone urbaine à Koumassi (Abidjan), Côte d'Ivoire
}

\author{
K. SORO ${ }^{1 *}$, F. SÉGUÉNA ${ }^{2}$, A.D.E. AMON ${ }^{3}$ et B.B. KONAN ${ }^{1}$ \\ ${ }^{1}$ Centre de Recherche en Ecologie de l'Université Nangui Abrogoua 08 BP 109 Abidjan 08, Côte d'Ivoire. \\ ${ }^{2}$ Université Péléforo Gon Coulibaly, Institut de Gestion Agropastorale. BP 1328 Korhogo, Côte d'Ivoire. \\ ${ }^{3}$ Université Jean Lorougnon Guedé, UFR Agroforesterie. BP 150 Daloa, Côte d'Ivoire. \\ "Auteur correspondant ; E-mail: skafanal @yahoo.fr; Tel: 0022508494739
}

\section{RESUME}

La diversité floristique associée à la culture de la menthe en zone urbaine est méconnue. La composition floristique d'une parcelle de culture maraîchère à base de menthe a été étudiée L'objectif de l'étude est de mieux faire connaître les espèces de flore rencontrées sur les sites d'exploitation de la menthe et l'évolution de celles des adventices au cours de la croissance des menthes. Par la méthode de relevé de surface, l'inventaire de la flore a été faite. Les résultats ont montré une richesse floristique du site d'étude de 46 espèces reparties en 34 genres et en 20 familles. Cette flore se compose d'espèces cultivées et d'espèces spontanées constituant la flore adventice. Le premier groupe d'espèces comprend deux (2) espèces de menthe (Mentha spicata et Mentha piperita) de la famille des Lamiaceae constituant la culture principale et se propagent facilement par boutures. Vingt-six (26) autres espèces légumières exploitées soit en association ou en accompagnement à la culture de menthe. Parmi ces dernières, les espèces les mieux représentées sont Colocasia esculenta, Amaranthus hybridus et Cleome gynandra, Cleome gynandra, Cymbopogon citratus, Hibiscus sabdariffa. Les besoins alimentaires sont les plus exprimés pour ces espèces à travers principalement les feuilles. Le deuxième groupe est constitué de 18 espèces d'adventices qui se regroupent dans 14 genres et 10 familles. La flore adventice est dominée par Cyperus rotondus, Heliotropium indicum, Phyllantus amarus, Euphorbia hirta, Portulaca oleracea. Le nombre d'espèces des adventices diminue au fur et à mesure que le désherbage est effectué jusqu'à la récolte.

(C) 2018 International Formulae Group. All rights reserved.

Mots clés: Culture, menthe, espèces légumières, flore, légumes, adventices, Abidjan.

\section{Characterization of flora in vegetable plants areas: case of a plot of mint in the urban area in Koumassi (Abidjan), Ivory Coast}

\begin{abstract}
The floristic diversity associated with the cultivation of mint in urban areas is unknown. The floristic composition of a parcel of mint-based vegetable cultivation has been studied. The objective of the study is to known the species of flora found on mint exploitation sites and the evolution of those of weeds during the growth of mints. By the method of surface survey, the inventory of the flora was made. The results showed a floristic richness of the study site of 46 species divided into 34 genera and 20 families. This flora is composed of cultivated species and spontaneous species constituting the adventitious flora. The first group of species
\end{abstract}


includes two (2) species of mint (Mentha spicata and Mentha piperita) of the Lamiaceae family constituting the main crop and propagates easily by cuttings. Twenty-six (26) other vegetable species exploited either in association with or in support of mint cultivation. Among the latter, the best represented species are Colocasia esculenta, Amaranthus hybridus and Cleome gynandra, Cleome gynandra, Cymbopogon citratus, Hibiscus sabdariffa. The food requirements for humans are the most expressed for these species mainly through the leaves. The second group consists of 18 weed species that are grouped into 14 genera and 10 families. The weed flora is dominated by Cyperus rotondus, Heliotropium indicum, Phyllantus amarus, Euphorbia hirta and Portulaca oleracea. The number of weed species decreases as weeding is done until harvest.

(C) 2018 International Formulae Group. All rights reserved.

Keywords: Cultivation, mint, vegetable species, flora, vegetables, weeds, Abidjan.

\section{INTRODUCTION}

La menthe est une plante herbacée et vivace. Elle comporte généralement des feuilles dentelées et pointues. Elle est plus ou moins parfumées en fonction de la variété et est principalement cultivée pour son odeur (parfumerie), ses qualités gustatives à travers une essence qui contient le menthone et du menthol qui sont des aromatiques rafraîchissants (Korichi, 2007) et ses bienfaits en phytothérapie à partir notamment des huiles essentielles produites (HAMMAMI et ABDESSELEM, 2004; Benayad, 2008 et Abbes, 2014). La menthe comporte plusieurs espèces appartenant à la famille des Lamiaceae. Elle constitue une des cultures maraîchères régulièrement rencontrées en Côte d'Ivoire. Plus de 40 espèces de cultures maraîchères sont cultivées en Côte d'Ivoire (CNRA, 2015). Ces espèces qui sont essentiellement des légumes, sont diversement exploitées dans les zones rurales, urbaines et périurbaines. Les légumes ont une grande importance pour l'alimentation de la population urbaine dont la forte croissance de ces dernières décennies entraîne une augmentation de la demande en Côte d'Ivoire et dans d'autres pays comme le Bénin (Atidegla et al., 2011) où le maraîchage est devenu un nouveau métier et joue un rôle important dans l'approvisionnement en légumes frais. Déjà en 2001, la production légumière avait progressé de $30 \%$ en une dizaine d'années pour atteindre 700000 tonnes (Fondio et al., 2011). Des études se sont penchées sur ces cultures maraîchères. Cependant, ces dernières se sont intéressées aux espèces légumières, leur traitement phytosanitaire et leur mode d'exploitation et non à la totalité de la flore rencontrées dans leurs sites d'exploitations. C'est le cas des travaux sur la gestion des pesticides dans les zones d'exploitation des cultures maraîchères en Côte d'Ivoire, au Bénin, au Tchad et au Kenya notamment (Ton, 2000 ; Doumbia et Kwadjo, 2009).

Dans les zones urbaines et périurbaines d'Abidjan et plus précisément dans la commune de Koumassi, de nombreuses espèces exotiques notamment la laitue, le chou, le persil, le poireau, l'épinard, la menthe, la carotte, etc. sont cultivées. Dans le cadre de cette étude, le travail a concerné la diversité floristique rencontrée dans les parcelles de maraichage à base de menthe qui, comme les autres cultures maraîchères, sont aussi rentables et possèdent en plus des vertus thérapeutiques et alimentaires (Douay, 2008). Cependant, au plan spécifique, les menthes sont peu connues et cela l'est encore moins pour la diversité floristique associée à leur culture. La méconnaissance de la flore des sites d'exploitation de la menthe pourrait être liée au nombre réduit de travaux scientifiques y afférents. Une telle connaissance contribuerait par exemple à affiner l'itinéraire technique de la culture de la menthe en luttant à temps contre les adventices, à améliorer la lutte intégrée contre les principaux ravageurs, à préciser les usages des espèces végétales spontanées sur les aires de culture de la menthe, etc. L'objectif général de ce travail est de mieux faire connaître des espèces de flore rencontrées sur les sites d'exploitation de 
la menthe notamment en zone urbaine. De façon spécifique, il s'agit de connaître les espèces de menthe exploitées localement, celles des plantes associées intentionnellement, celles des espèces qui se sont développées spontanément et des usages qui en sont faits.

\section{MATERIEL ET METHODES}

\section{Localisation du site d'étude}

L'étude s'est déroulée en zone urbaine dans la commune de Koumassi, l'une des 10 communes de la ville d'Abidjan, Capitale économique de la Côte d'Ivoire. La commune de Koumassi est située au Sud de la lagune Ebrié entre $5^{\circ} 18^{\prime} 12^{\prime \prime}$ de latitude Nord et $4^{\circ}$ $00^{\prime} 33^{\prime \prime}$ de longitude Ouest à une altitude dont la minimale est $9 \mathrm{~m}$ et la maximale $30 \mathrm{~m}$ audessus du niveau de la mer. Le site d'étude est une parcelle de cultures maraîchères, localisée en bordure de la lagune Ebrié (Figure 1).

Quatre saisons climatiques caractérisent la commune de Koumassi : une grande saison pluvieuse (mars à juillet) et une petite saison pluvieuse (septembre à novembre) qui alternent avec une grande saison sèche (décembre à février) et une petite saison sèche au cours du mois d'août. Il tombe en moyenne $1784 \mathrm{~mm}$ de pluie par an. La température moyenne annuelle est de $26,6{ }^{\circ} \mathrm{C}$.

La parcelle d'étude couvre une superficie de $3200 \mathrm{~m}^{2}$ en raison de $40 \mathrm{~m}$ de largeur et $80 \mathrm{~m}$ de longueur. Elle comporte des planches sur lesquelles sont plantées les boutures de menthe (Figure 2), un site de stockage de fiente de poulet qui sert de fertilisant (Figure 3) et 6 puits disséminés dans la parcelle pour servir à l'arrosage des cultures (Figure 4). Sur les planches, d'une superficie moyenne de $10,5 \mathrm{~m}^{2}$, les boutures de menthe de taille variables sont plantées par poquets en raison de 2 à 4 boutures/poquets. Les poquets sont distants de $12 \mathrm{~cm}$ en ligne et $18 \mathrm{~cm}$ en interligne avec une densité moyenne de 46 poquets $/ \mathrm{m}^{2}$. Aux abords de chaque planche, des spécimens d'autres espèces de cultures (oseille, épinard, etc.) ont été plantés.

\section{Matériel végétal}

Le matériel végétal est constitué de toutes les espèces végétales rencontrées dans la parcelle de cultures maraîchères à base de la menthe.

\section{Méthodes}

L'inventaire des espèces végétales a été fait par la méthode de relevé de surface qui consiste à délimiter des parcelles pour collecter les données et permet de recenser le maximum d'espèces (Adou et al., 2016). Pour les espèces de culture, douze (12) planches ont été choisies de façon aléatoire dans la parcelle. Chacune des planches choisies a été échantillonnée systématiquement. Pour connaître l'évolution de la flore adventice, 3 planches ont été confectionnées et plantées par espèces de menthe et selon la méthode du maraîcher. Les planches ont une longueur moyenne de $7 \mathrm{~m}$ et une largeur moyenne de $1,5 \mathrm{~m}$. Chacune de ces planches a été échantillonnée à trois stades de développement des menthes : à la fin des deux premières semaines qui ont suivi la mise en terre des boutures de menthe; à la fin de la troisième semaine et à la récolte à la fin de la quatrième semaine. La liste de la flore a été complétée par la méthode de relevé itinérant qui a permis de parcourir la parcelle dans divers sens.

Pour éviter des pertes d'informations sur les espèces spontanées, l'inventaire est intervenu juste avant chaque étape de désherbage des planches ou de récolte des menthes. Des parcours itinérants ont permis également de prendre en compte des espèces qui se retrouvent de façon isolée dans la parcelle de menthe. Pour chaque espèce inventoriée, le nom scientifique est enregistré lorsqu'il est identifié. Dans le cas contraire, le spécimen est prélevé pour être identifié plus tard au laboratoire. L'identification des espèces a été faite à l'aide de la consultation de divers ouvrages. Ce sont ceux de Angaman et al. (2001) et Sangaré et al. (2009) qui présentent des espèces de cultures maraîchères. La consultation de l'internet a 
été d'un grand apport pour l'identification des espèces de flore. Par une enquête agricole, des informations ont été prises auprès de 3 personnes dont le maraîcher et deux femmes vendeuses qui achètent la menthe sur planche afin d'apprécier la qualité des espèces inventoriées.
Les valeurs obtenues sur l'évolution du nombre d'espèces adventices par stade de développement des menthes ont été analysées statistiquement à travers le logiciel XLSTAT 2014.5.01. Ce programme prévoit, en cas de différences significatives, une comparaison de moyennes par le test de Newman-Keuls au risque $\alpha=5$ p.c.

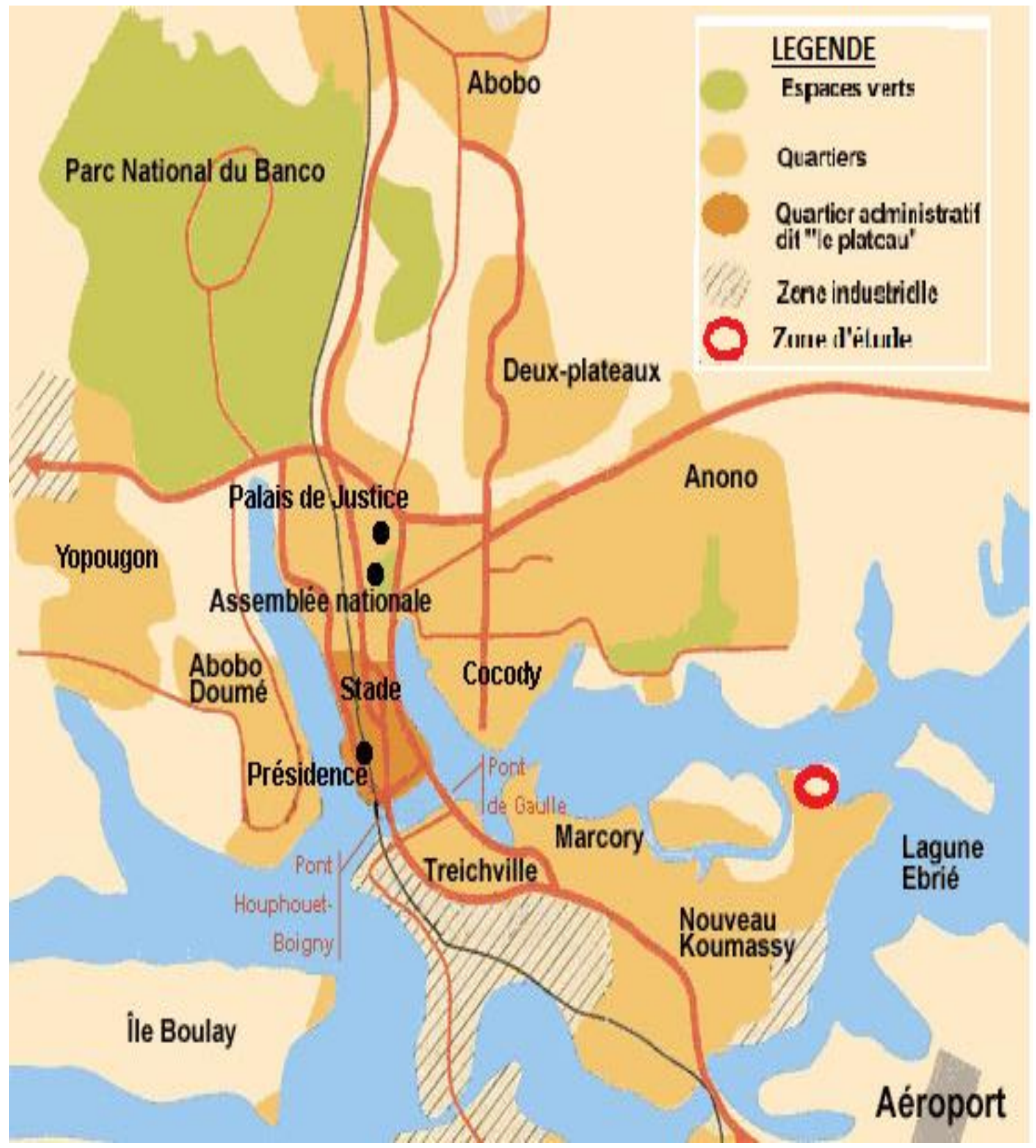

Figure 1 : Localisation du site d'étude sur la carte de la ville d'Abidjan. 


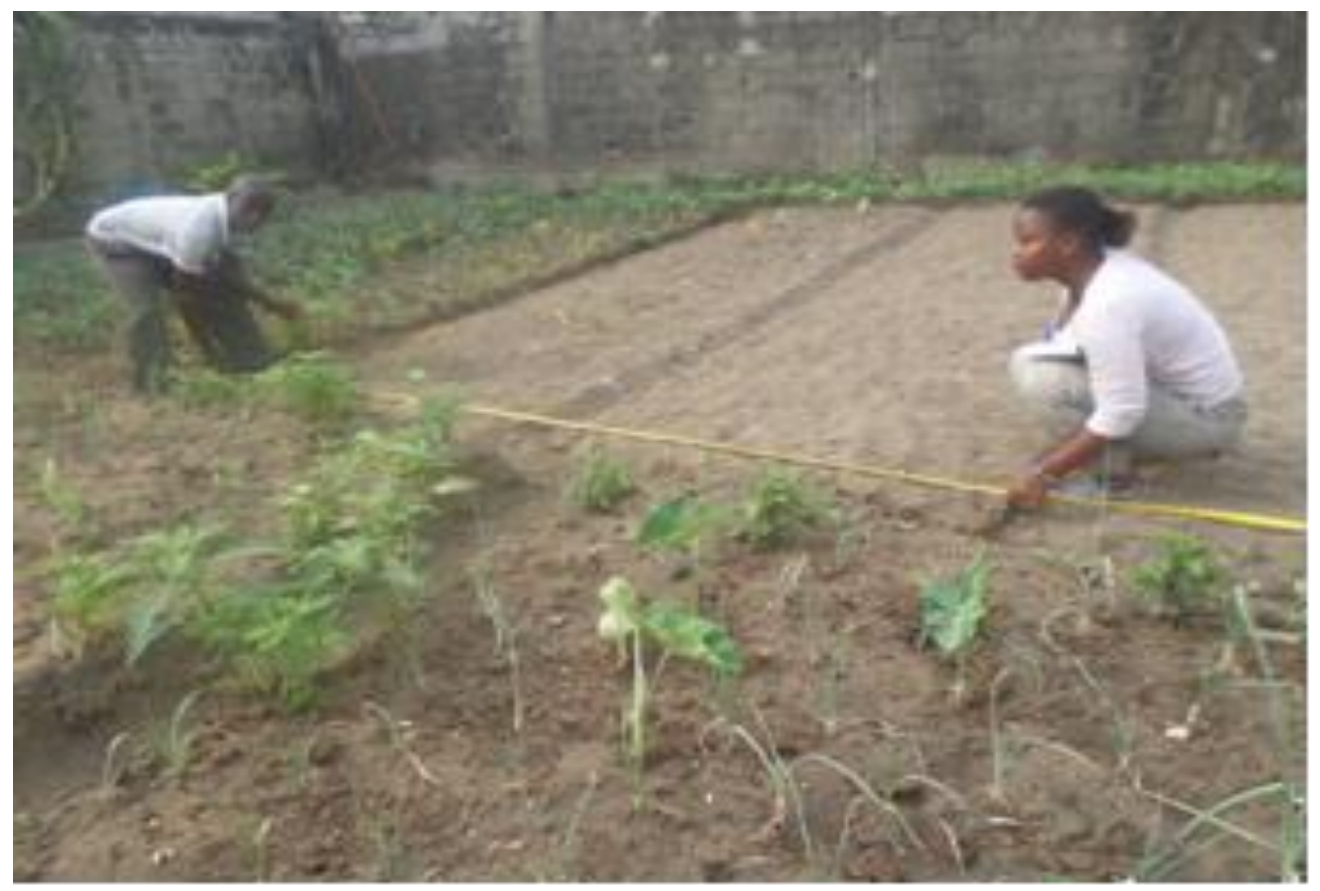

Figure 2 : Confection et mesure des planches devant recevoir les boutures de menthe.

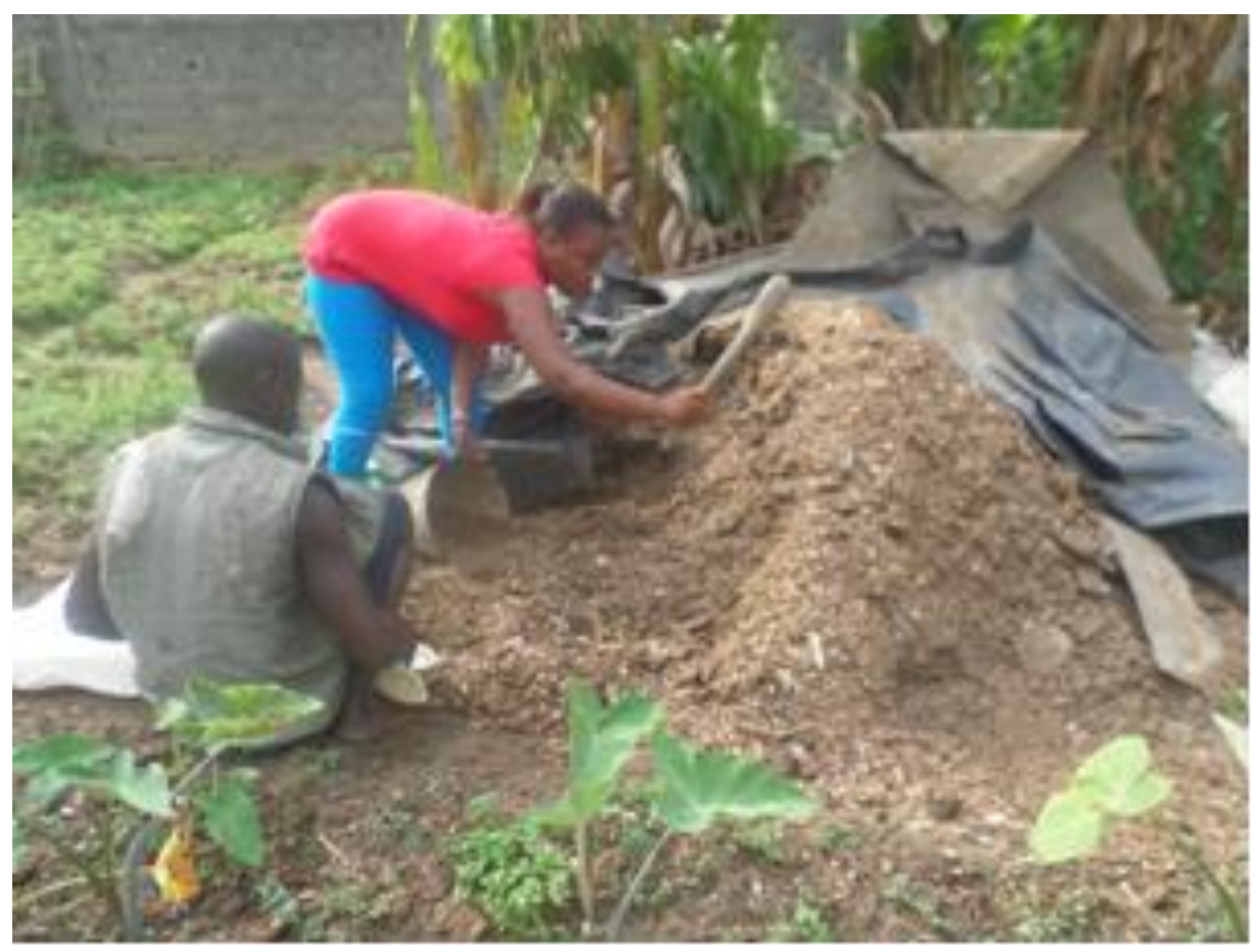

Figure 3 : Prélèvement de fiente de poulet sur le site de stockage. 


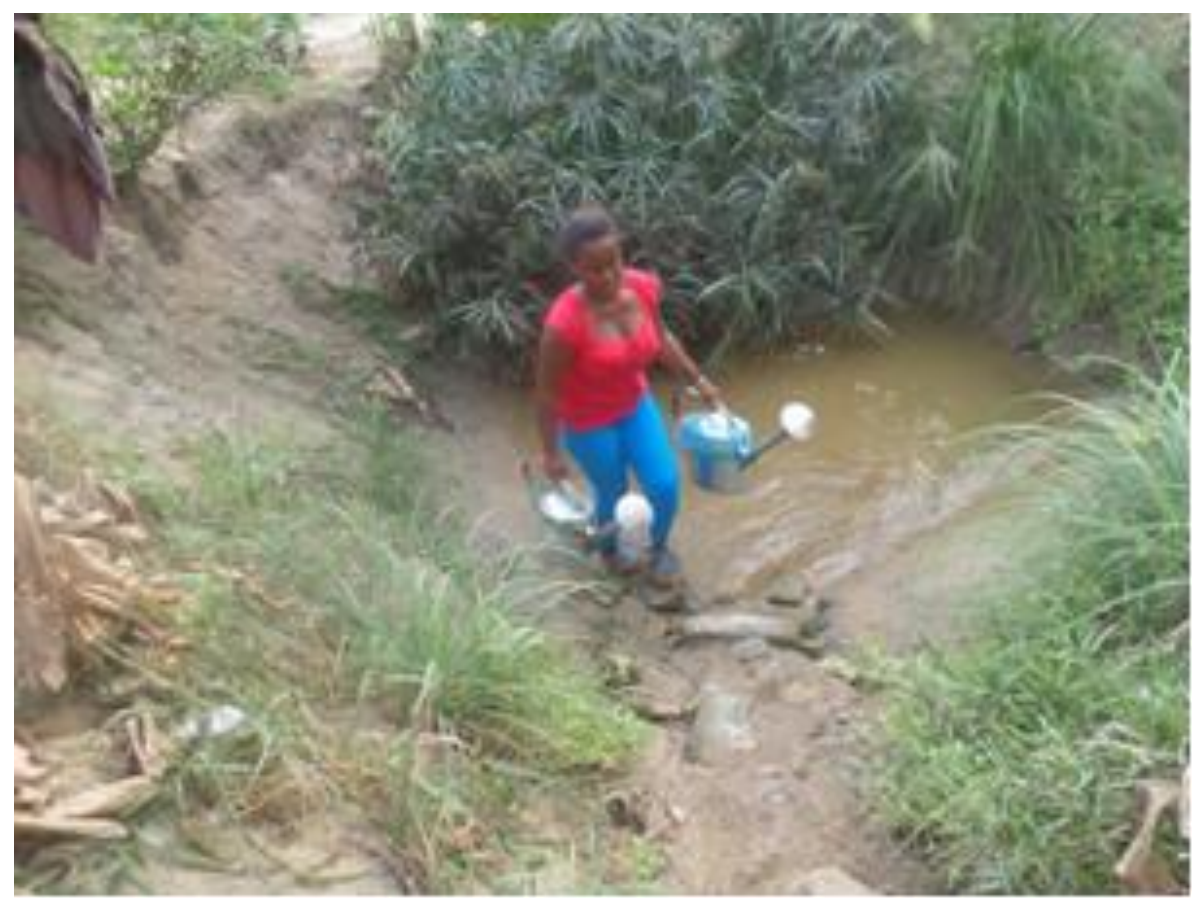

Figure 4 : Un puits servant de point d'eau pour l'arrosage.

\section{RESULTATS}

L'étude a permis d'identifier 28 espèces végétales qui se répartissent en cultures principales (la menthe), en cultures associées ou d'accompagnement et en espèces spontanées d'adventices (les mauvaises herbes).

\section{Espèces cultivées}

Vingt-huit (28) espèces légumières cultivées ont été inventoriées sur le site d'étude. Elles appartiennent à 21 genres et 20 familles.

\section{Espèces de menthe}

Deux espèces de menthe ont été rencontrées. Il s'agit de la menthe verte naine $\mathrm{du}$ Maroc (Mentha spicata) et la menthe poivrée (Mentha piperita) qui sont présentées respectivement par les Figures 5 et 6. Elles appartiennent à la famille des Lamiaceae. Les descriptions peuvent être faites de la manière suivante :

- Menthe verte: Mentha spicata L. (Lamiaceae). La menthe verte (Mentha spicata L.) est une plante vivace, robuste, de
$50 \mathrm{~cm}$ à 1 mètre, d'un vert sombre, à odeur suave très pénétrante (Figure 5). Les feuilles sont opposées persistantes, lancéolées, aigües, dentées en scie, vertes sur les 2 faces, glabres ou presque glabres. L'implantation des feuilles est paripennée et décussée (avec un angle de $90^{\circ}$ ). Elles sont persistantes. La tige de la menthe verte naine du Maroc est dite quadrangulaire (carrée) ascendante (orthotrope). Elle est de couleur pourpre. La taille de la menthe verte peut atteindre au maximum une hauteur de $1,20 \mathrm{~m}$ mais en moyenne varie entre 0,30 et $0,60 \mathrm{~cm}$. Les racines sont observées en dessous de chaque pied.

- Menthe poivrée: Mentha piperita L. (Lamiaceae). La menthe poivrée (Mentha piperita L.) est une plante herbacée, vivace à drageon, hémicryptophyte (Figure 6). Elle se dresse de $10 \mathrm{~cm}$ jusqu'à $75 \mathrm{~cm}$, voire $1 \mathrm{~m}$ de hauteur. Les tiges et les rameaux sont rougeâtres, à section carrée. Les feuilles sont opposées et décussées. Ce sont les feuilles simples, pétiolées, de 4 à $10 \mathrm{~cm}$ de long, velues et d'un vert foncé sur la face 
supérieure, se teignant de nuances rougeâtres au soleil et de rouge cuivré à l'ombre. Elles sont ovale-lancéolées à marge dentée.

- Modes de propagation des menthes. Le mode de reproduction qui a été enregistré chez les menthes est celui des boutures de tiges. Sur ces dernières, l'enracinement se fait assez rapidement. Chez la menthe poivrée, un enracinement vigoureux a été enregistré sur les 2 tiers des boutures ( 6 boutures/9) à partir $\mathrm{du} 3^{\mathrm{e}}$ jour. A partir du $4^{\mathrm{e}}$ jour, toutes les boutures ont présenté des racines (Figure 7). Chez la menthe verte, un faible enracinement a été enregistré sur 1 tiers des boutures (3 boutures/9) le $3^{\mathrm{e}}$ jour. Le $4^{\mathrm{e}}$ jour, 2 tiers des boutures ont porté des racines (Figure 8). L'enracinement total n'a pu être observé qu'après une semaine. Après observation, le constat a indiqué que les racines apparaissent sur les boutures âgées avant les boutures moins âgées qui s'enracinent plus tard.

\section{Autres espèces légumières associées aux menthes}

Parmi les 28 espèces cultivées recensées sur le site d'exploitation des menthes 8 espèces ont été présentées comme celles pouvant être plantées en ligne sur les bordures des planches de culture principale. Ce sont : Amaranthus hybridus, Basella alba, Celosia argentea, Corchorus olitorius, Corchorus tridens, Hibiscus sabdariffa, Solanum macrocarpon et Solanum nigrum. Dans le cadre de ce travail, ce sont les espèces de Amaranthus hybridus (Figure 9), Basella alba et Corchorus olitorius qui ont été utilisées. En plus de ces espèces, 20 autres espèces d'intérêt économique ont été retrouvées de façon disparate ou isolée dans la parcelle de menthe. Ce sont notamment Abelmoschus esculentus, Cymbopogon citratus, Ipomoea batatas et Manihot esculenta. Les différents organes aériens de ces plantes sont utilisés, selon l'espèce, avec une prédominance pour l'alimentation (Figure 10). Divers organes des espèces légumières sont utilisés, feuilles étant les plus dominantes (Figure 11).

$\mathrm{Au}$ plan floristique, Colocasia esculenta, Amaranthus hybridus et Cleome gynandra sont les espèces les mieux distribuées dans la parcelle avec respectivement des fréquences relatives supérieures à $10 \%$ et qui avec Cleome gynandra L., Cymbopogon citratus (DC.) Stapf, Hibiscus sabdariffa L. et Mentha piperita L. totalisent plus de 56\% (Tableau 1). La liste des espèces de culture inventoriées a été complétée par celles issues de l'inventaire itinérant qui sont: Vernonia amygdalina Delile (Asteraceae) ou «Kôsafina en Malinké », Saccharum officinarum L. (Poaceae) ou canne à sucre, Musa paradisiaca L. (Musaceae) ou Banane plantain, Musa esculenta L. (Musaceae) ou Banane douce, Moringa oleifera Lam. (Moringaceae) ou Moringa ou «Gnougou en malinké » et Manihot esculenta Crantz (Euphorbiaceae) ou manioc.

\section{Espèces spontanées d'adventices}

Au cours de la croissance des plants de menthes, de nombreuses espèces adventices se sont développés. Au total, dix-huit (18) espèces ont été identifiées au cours des trois stades de développement des menthes. Elles se répartissent dans 10 familles dont les plus représentées sont par ordre de grandeur les Euphorbiaceae, les Poaceae, les Caesalpiniaceae et les Portulacaceae (Figure 12). Quelques-unes de ces espèces adventices inventoriées, telles que Cassia occidentalis, Eclipta prostrata, Heliotropium indicum et Portulaca oleracea, sont utilisées comme des plantes médicinales. Les différents organes de certaines plantes sont utilisés, selon l'espèce, pour des soins.

Les résultats de l'analyse statistique indiquent que le nombre moyen d'adventices dans chacun des types de menthe pris individuellement, ne présente pas de différence significative pour les planches et diffère statistiquement d'un stade de croissance à un autre (Tableaux 2 et 3 ). Lorsque les deux types de menthe sont considérés ensemble, le nombre moyen d'adventices ne présente pas de différence significative pour les planches et diffère statistiquement du stade de développement à 2 semaines par rapport à celui des deux autres stades de développement (3 semaines et 
récoltes) qui sont statistiquement identiques (Tableau 4).

Au plan floristique, Cyperus rotondus L., Heliotropium indicum L., Phyllantus amarus Schum. \& Thonn. et Euphorbia hirta L. sont les espèces les plus présentes avec respectivement des fréquences relatives supérieures à $10 \%$ et qui avec Portulaca oleracea L. totalisent plus de 54\% (Tableau 5). La liste des espèces d'adventice inventoriées a été complétée par celles issues de l'inventaire itinérant qui sont : Eleusine indica L (Poaceae), Senna obtusifolia (L.) H.S. Irwin \& Barneby (Caesalpiniaceae) et Senna occidentalis (L.) Link (Caesalpiniaceae).

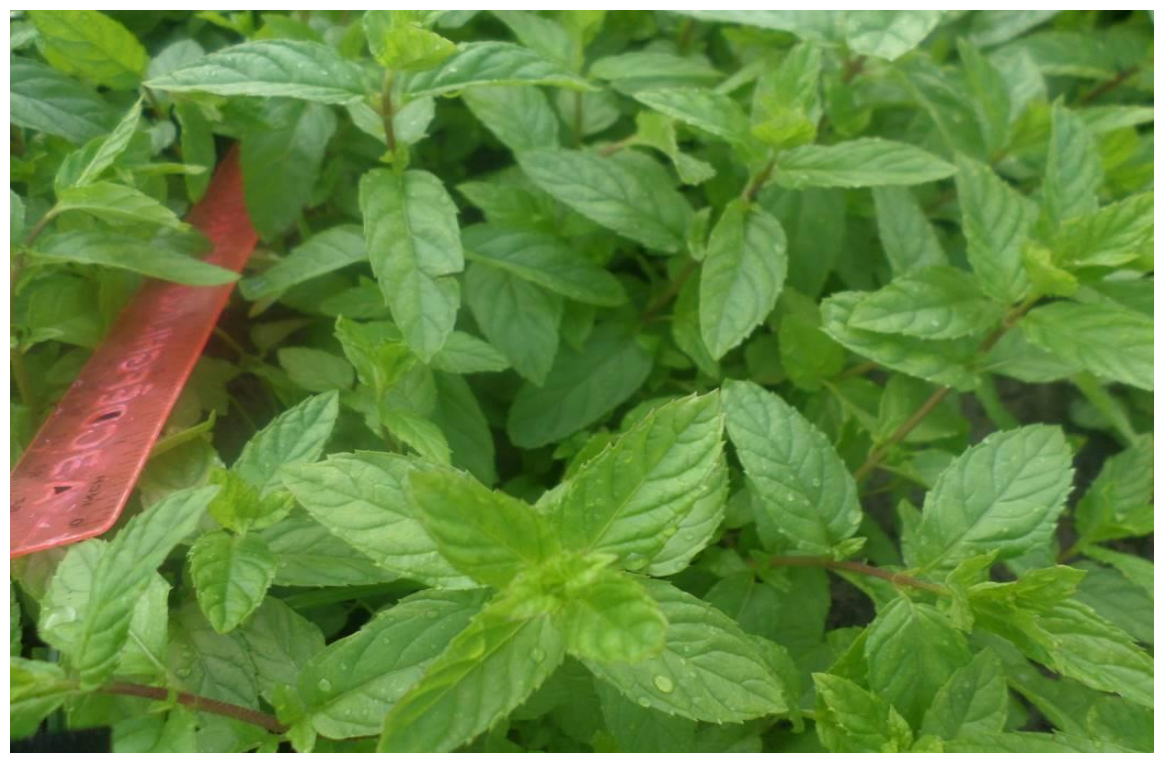

Figure 5 : Des tiges de menthe verte : Mentha spicata L. (Lamiaceae).

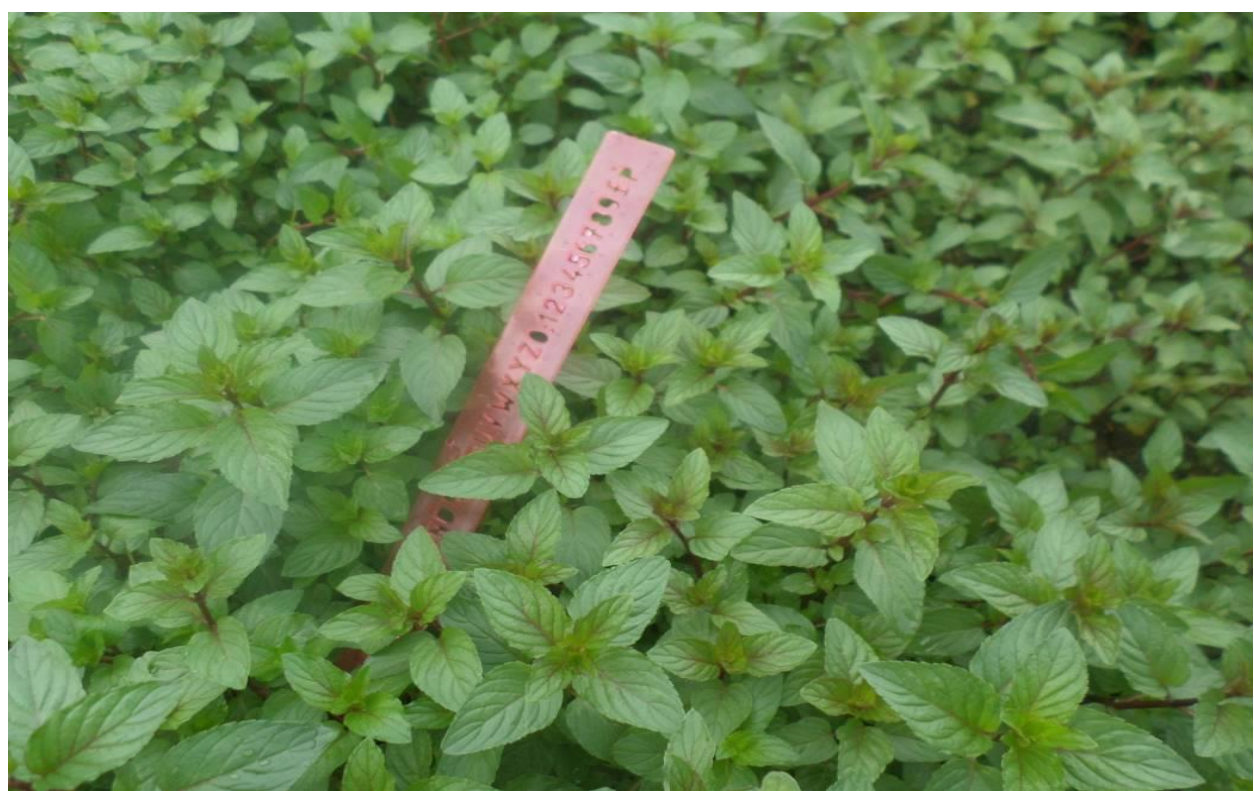

Figure 6 : Des tiges de menthe poivrée : Mentha piperita L. (Lamiaceae). 


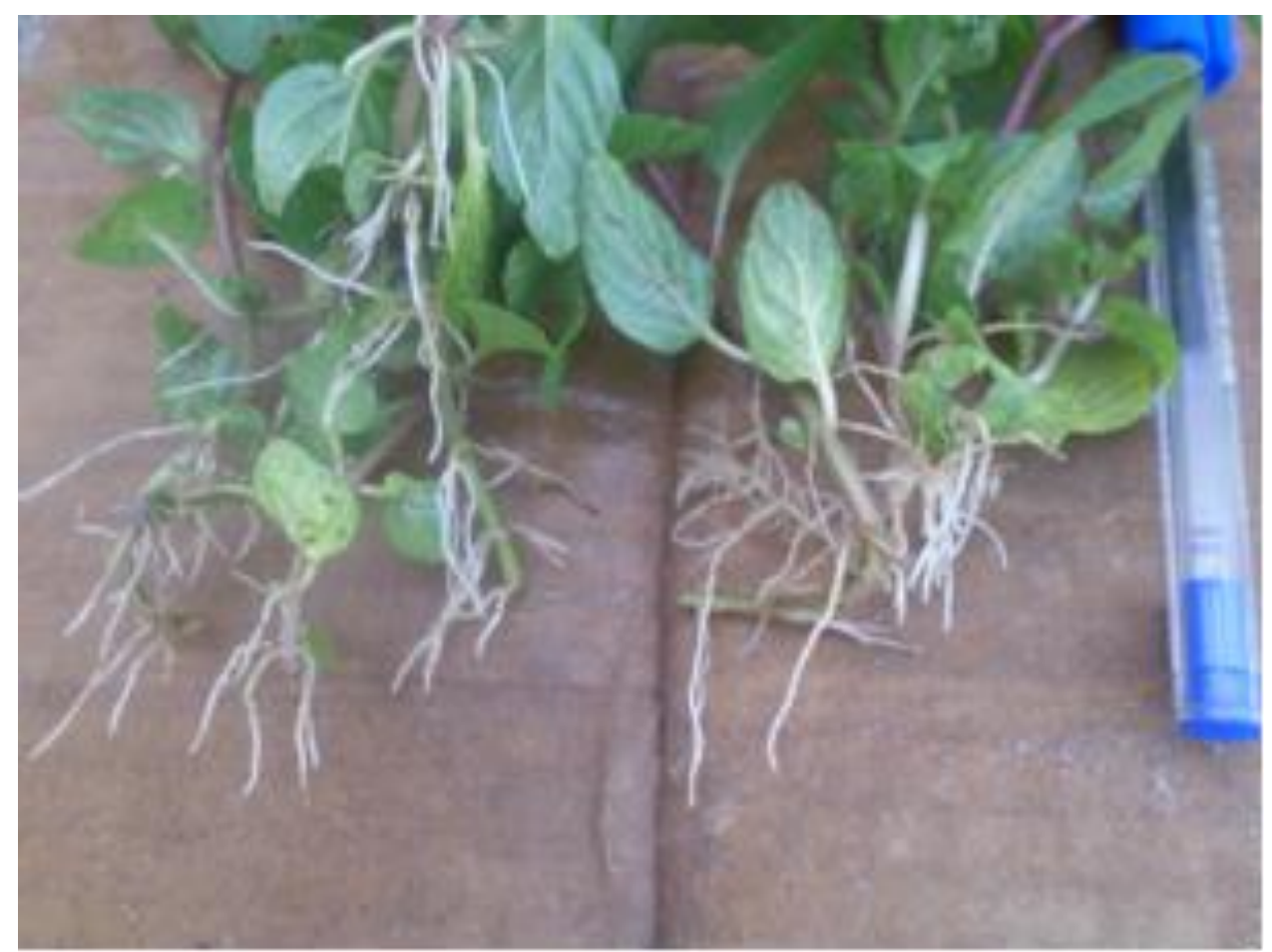

Figure 7 : Enracinement fort et total des plants âgés de 5 jours de la menthe poivrée.

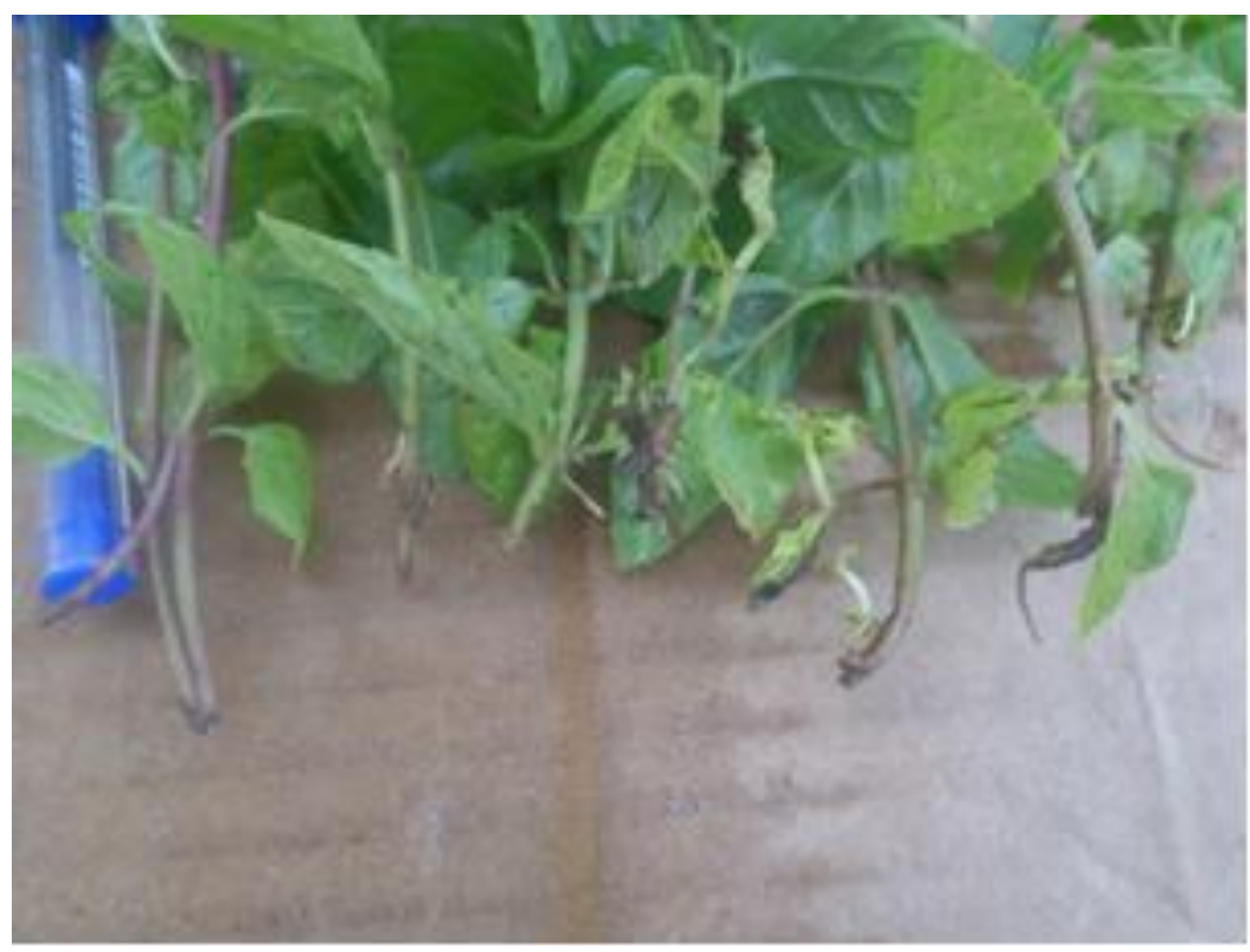

Figure 8 : Enracinement faible et partiel des plants âgés de 5 jours de la menthe verte. 


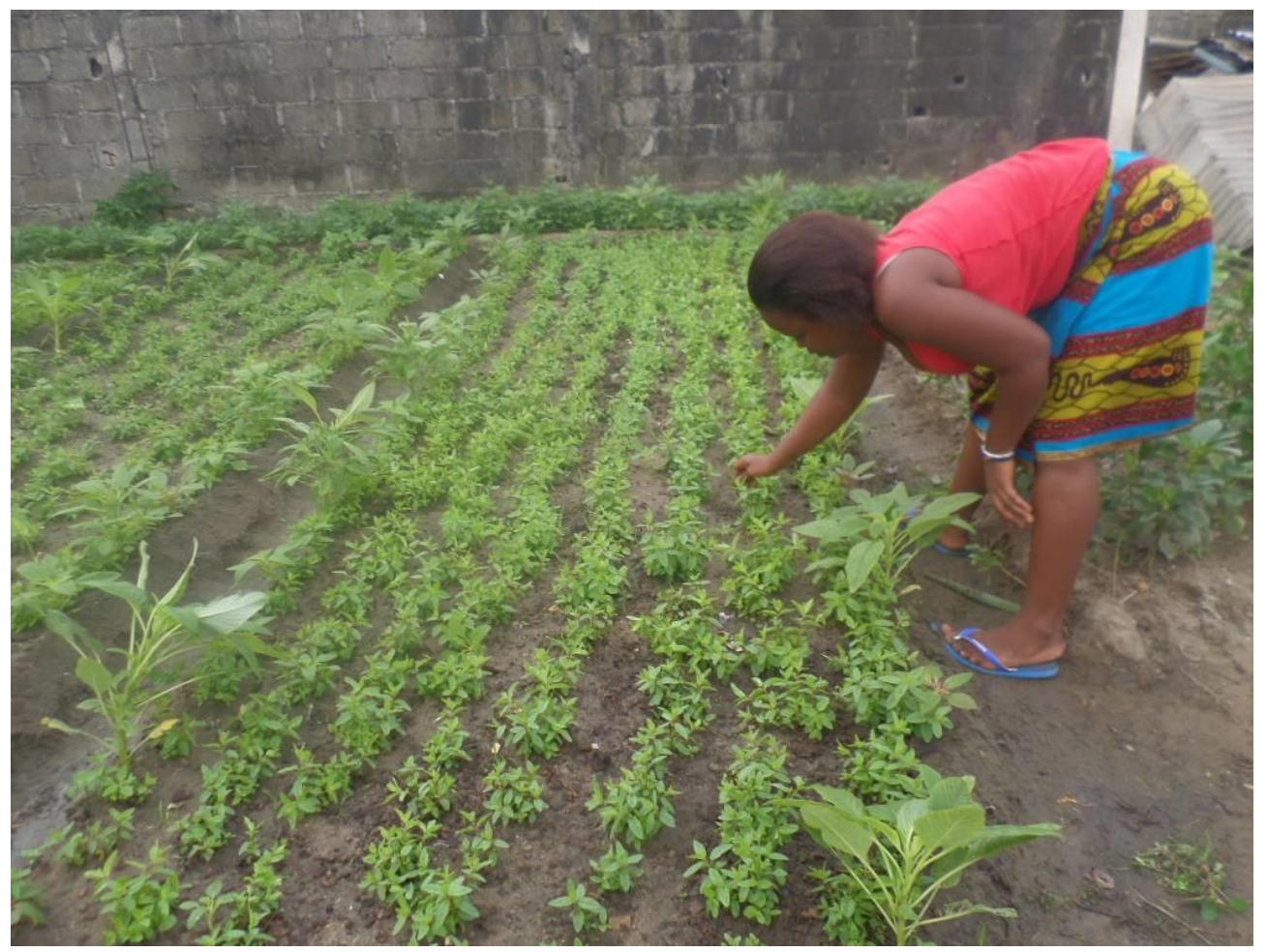

Figure 9 : Désherbage d'une planche de Mentha piperita comportant Amaranthus hybridus comme plante de bordure.

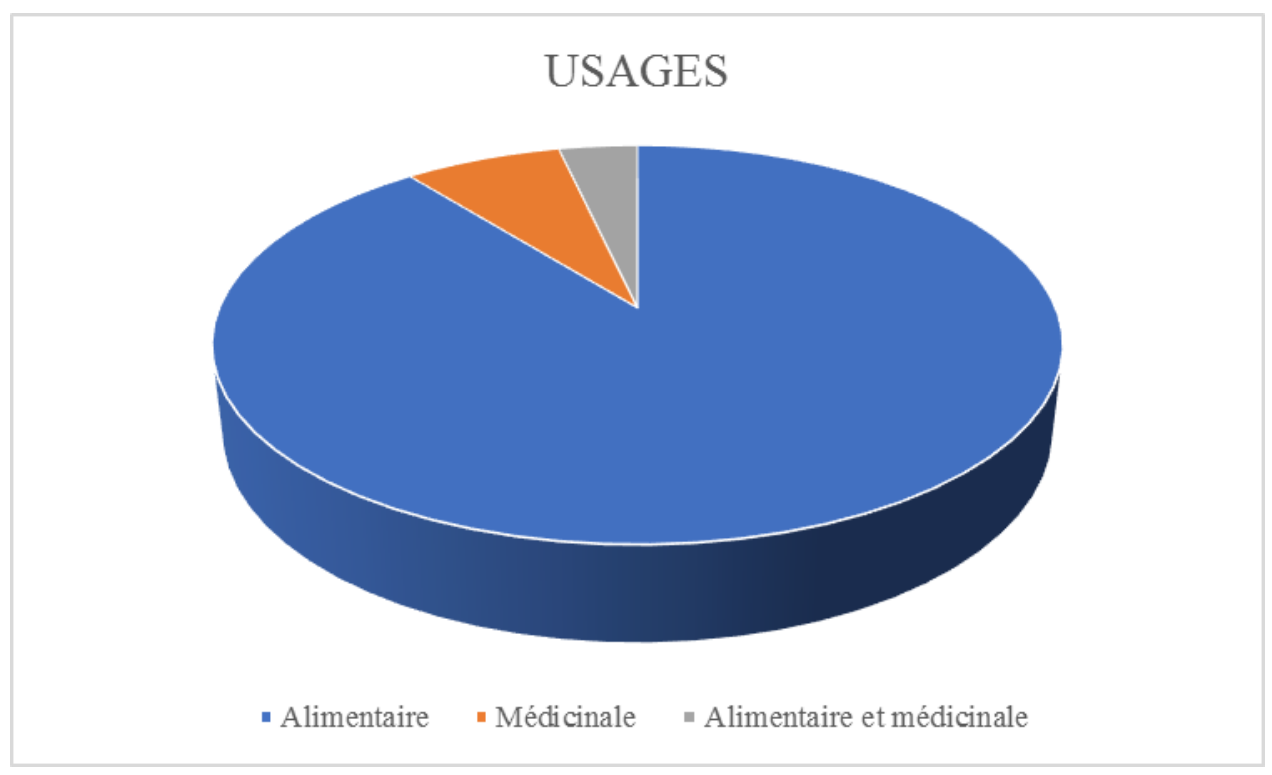

Figure 10: Usages des espèces légumières cultivées sur le site d'étude. 


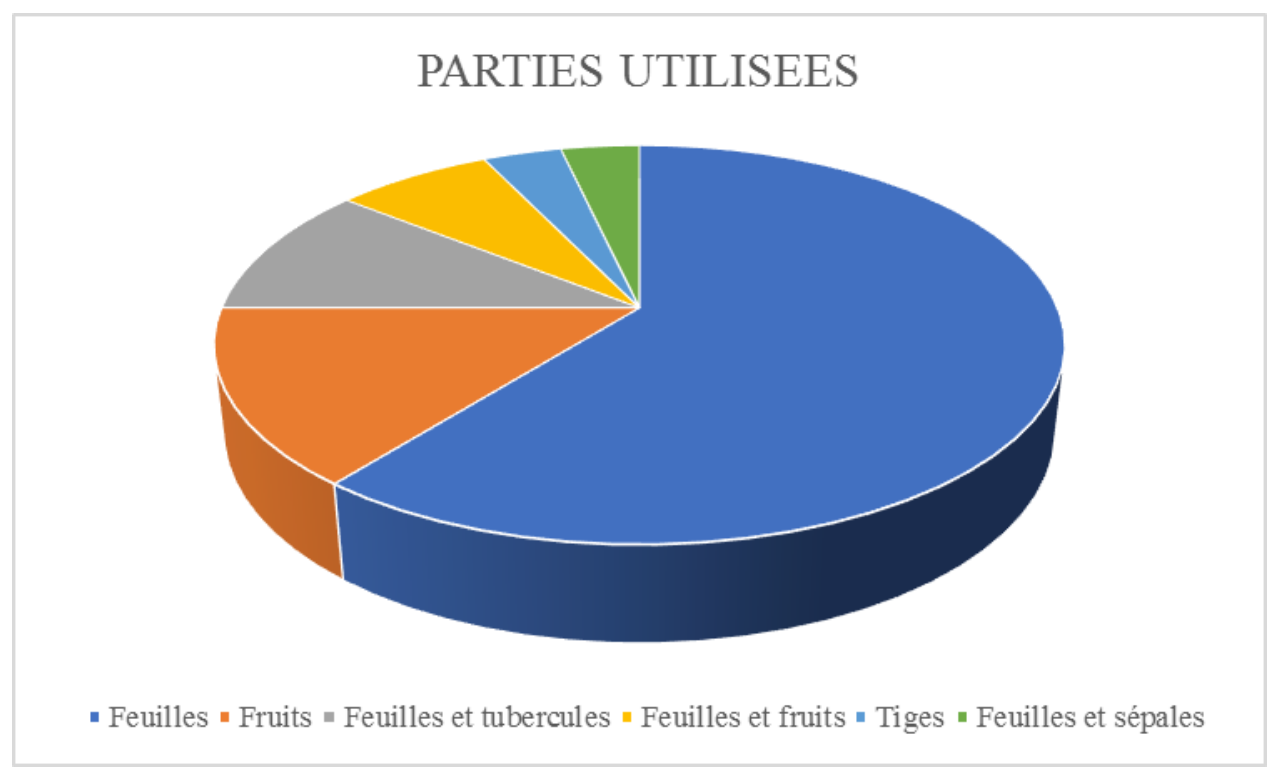

Figure 11: Parties utilisées des espèces légumières cultivées sur le site d'étude.

Tableau 1: Liste des espèces légumières inventoriées, selon les fréquences décroissantes, dans la parcelle de maraîchage.

\begin{tabular}{|c|c|c|c|c|}
\hline Espèces & Familles & $\begin{array}{l}\text { Noms } \\
\text { communs et } \\
\text { locaux }\end{array}$ & $\begin{array}{c}\text { Fréquences } \\
\text { absolues }\end{array}$ & $\begin{array}{l}\text { Fréquences } \\
\text { relatives (\%) }\end{array}$ \\
\hline Colocasia esculenta (L.) Schott & Araceae & Taro & 12 & 11,65 \\
\hline Amaranthus hybridus L. & Amaranthaceae & $\begin{array}{l}\text { Amarante } \\
\text { hybride ou } \\
\text { Bonombrou en } \\
\text { malinké }\end{array}$ & 11 & 10,68 \\
\hline Cleome gynandra $\mathrm{L}$. & Capparaceae & Win-win & 10 & 9,71 \\
\hline Cymbopogon citratus (DC.) Stapf & Poaceae & Citronnelle & 9 & 8,74 \\
\hline Hibiscus sabdariffa L. & Malvaceae & $\begin{array}{l}\text { Oseille ou dâh } \\
\text { en malinké }\end{array}$ & 8 & 7,77 \\
\hline Mentha piperita $\mathrm{L}$. & Lamiaceae & Menthe poivrée & 8 & 7,77 \\
\hline Talinum triangulare (Jacq.) Willd. & Portulacaceae & $\begin{array}{l}\text { Épinard } \\
\text { sauvage }\end{array}$ & 6 & 5,83 \\
\hline Allium fistulosum L. & Liliaceae & $\begin{array}{l}\text { Ciboule ou } \\
\text { Oignon vert }\end{array}$ & 5 & 4,85 \\
\hline Basella alba $\mathrm{L}$. & Basellaceae & Épinard & 5 & 4,85 \\
\hline Capsicum аппиит $\mathrm{L}$. & Solanaceae & Gros piment & 5 & 4,85 \\
\hline Celosia argentea $\mathrm{L}$. & Amaranthaceae & $\begin{array}{l}\text { Célosie } \\
\text { argentée ou } \\
\text { soko en } \\
\text { malinké }\end{array}$ & 5 & 4,85 \\
\hline Mentha spicata $\mathrm{L}$. & Lamiaceae & $\begin{array}{l}\text { Menthe verte } \\
\text { ou nanahé }\end{array}$ & 3 & 2,91 \\
\hline
\end{tabular}




\begin{tabular}{|c|c|c|c|c|}
\hline Ocimum gratissimum $\mathrm{L}$. & Lamiaceae & Magninnin & 3 & 2,91 \\
\hline Corchorus olitorius L. & Tiliaceae & $\begin{array}{l}\text { Corète potagère } \\
\text { ou Kplala }\end{array}$ & 2 & 1,94 \\
\hline Corchorus tridens L. & Tiliaceae & $\begin{array}{l}\text { Corète à trois } \\
\text { dents ou Kplala }\end{array}$ & 2 & 1,94 \\
\hline Ocimum basilicum $\mathrm{L}$. & Lamiaceae & Basilic & 2 & 1,94 \\
\hline Solanum nigrum L. & Solanaceae & $\begin{array}{l}\text { Morelle } \\
\text { africaine ou } \\
\text { fouet en baoulé } \\
\text { en Baoulé }\end{array}$ & 2 & 1,94 \\
\hline $\begin{array}{l}\text { Abelmoschus esculentus (L.) } \\
\text { Moench }\end{array}$ & Malvaceae & Gombo & 1 & 0,97 \\
\hline Allium porum $\mathrm{L}$. & Liliaceae & Poireau & 1 & 0,97 \\
\hline Ipomoea batatas (L.) Lam. & $\begin{array}{l}\text { Convolvulacea } \\
\mathrm{e}\end{array}$ & Patate douce & 1 & 0,97 \\
\hline Solanum lycopersicum L. & Solanaceae & Tomate & 1 & 0,97 \\
\hline Solanum macrocarpon L. & Solanaceae & $\begin{array}{l}\text { Aubergine } \\
\text { africaine ou } \\
\text { Gboma }\end{array}$ & 1 & 0,97 \\
\hline
\end{tabular}

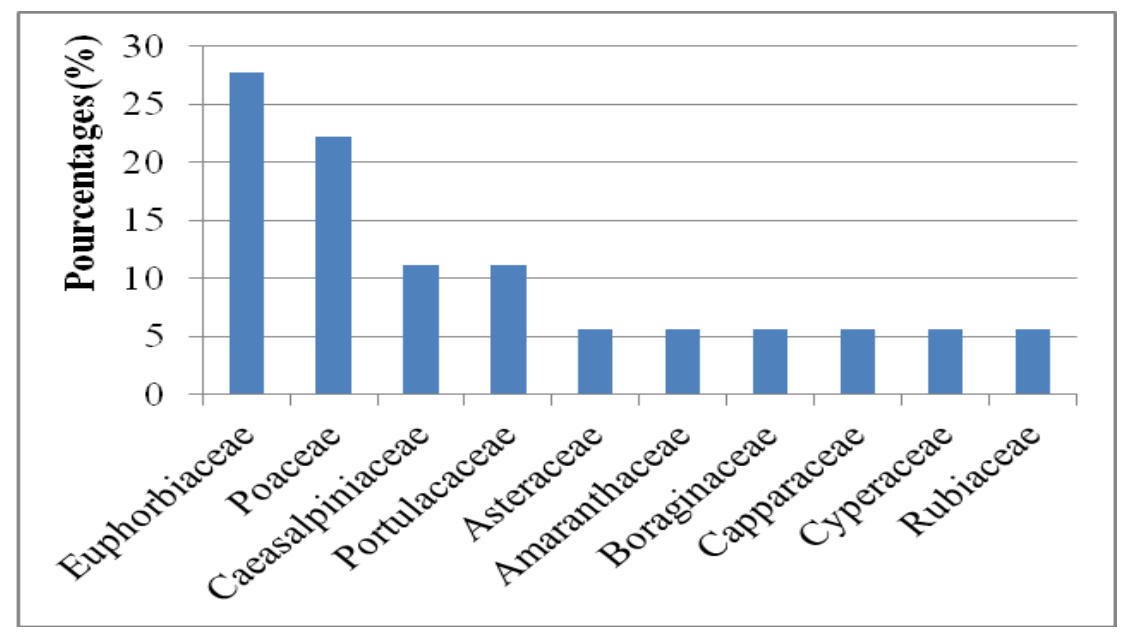

Figure 12 : Pourcentages des espèces adventices identifiées sur les planches de menthe selon les familles.

Tableau 2 : Comparaison des nombres moyens d'adventices selon les planches et les stades de développement de la menthe poivrée.

\begin{tabular}{|c|c|c|c|c|c|c|}
\hline Planches & $\begin{array}{l}\text { Nombre } \\
\text { d'adventic }\end{array}$ & $\begin{array}{l}\text { moyen } \\
\text { ees }\end{array}$ & $\begin{array}{l}\text { Groupes } \\
\text { homogènes }\end{array}$ & $\begin{array}{l}\text { Stades de } \\
\text { développement }\end{array}$ & $\begin{array}{l}\text { Nombres } \\
\text { d'adventices }\end{array}$ & $\begin{array}{l}\text { Groupes } \\
\text { homogènes }\end{array}$ \\
\hline Planche 1 & & $9,33 \mathrm{a}$ & & 2 sem. & $14,00 \mathrm{a}$ & 1 \\
\hline Planche 3 & & $9,00 \mathrm{a}$ & 1 & 3 sem. & $7,33 \mathrm{~b}$ & 2 \\
\hline Planche 2 & & 7,33 a & & Récolte & $4,33 \mathrm{c}$ & 3 \\
\hline Moyenne & 8,56 & & & Moyenne & 8,56 & \\
\hline Ecart-type & 4,42 & & & Ecart-type & 4,42 & \\
\hline C.V. (\%) & 51,63 & & & C.V. $(\%)$ & 51,63 & \\
\hline
\end{tabular}


Tableau 3 : Comparaison des nombres moyens d'adventices selon les planches et les stades de développement de la menthe verte.

\begin{tabular}{|c|c|c|c|c|c|}
\hline Planches & $\begin{array}{c}\text { Nombre } \\
\text { moyen } \\
\text { d'adventices }\end{array}$ & $\begin{array}{c}\text { Groupes } \\
\text { homogènes }\end{array}$ & $\begin{array}{c}\text { Stades de } \\
\text { développement }\end{array}$ & $\begin{array}{c}\text { Nombres } \\
\text { d'adventices }\end{array}$ & $\begin{array}{c}\text { Groupes } \\
\text { homogènes }\end{array}$ \\
\hline Planche 1 & $12,33 \mathrm{a}$ & \multirow{3}{*}{1} & 2 sem. & $14,33 \mathrm{a}$ & 1 \\
\hline Planche 2 & $11,66 \mathrm{a}$ & & $3 \mathrm{sem}$. & $11,66 \mathrm{ab}$ & 2 \\
\hline Planche 3 & $11,33 \mathrm{a}$ & & Récolte & $9,33 \mathrm{~b}$ & 3 \\
\hline Moyenne & 11,78 & & Moyenne & 11,78 & \\
\hline Ecart-type & 2,54 & & Ecart-type & 2,54 & \\
\hline C.V. (\%) & 21,56 & & C.V. (\%) & 21,56 & \\
\hline
\end{tabular}

Tableau 4 : Comparaison des nombres moyens d'adventices selon les planches, les stades de développement et le type de menthe.

\begin{tabular}{|c|c|c|c|c|c|c|c|c|}
\hline Planches & $\begin{array}{l}\text { Nombre } \\
\text { moyen } \\
\text { d'adventices }\end{array}$ & $\begin{array}{l}\text { Groupe } \\
\text { homogène }\end{array}$ & $\begin{array}{l}\text { Stades de } \\
\text { développement }\end{array}$ & $\begin{array}{l}\text { Nombre } \\
\text { moyen } \\
\text { d'adventices }\end{array}$ & $\begin{array}{l}\text { Groupes } \\
\text { homogènes }\end{array}$ & $\begin{array}{l}\text { Type de } \\
\text { menthe }\end{array}$ & $\begin{array}{l}\text { Nombre } \\
\text { moyen } \\
\text { d'adventices }\end{array}$ & $\begin{array}{l}\text { Groupe } \\
\text { homogène }\end{array}$ \\
\hline Planche 3 & $10,66 \mathrm{a}$ & \multirow{3}{*}{1} & 2 sem. & $14,16 \mathrm{a}$ & 1 & $\begin{array}{l}\text { Menthe } \\
\text { poivrée }\end{array}$ & $11,77 \mathrm{a}$ & \multirow{2}{*}{1} \\
\hline Planche 1 & $10,33 \mathrm{a}$ & & 3 sem. & $9,50 \mathrm{~b}$ & \multirow[t]{2}{*}{2} & $\begin{array}{l}\text { Menthe } \\
\text { verte }\end{array}$ & $8,55 \mathrm{a}$ & \\
\hline Planche 2 & $9,50 \mathrm{a}$ & & Récolte & $6,83 \mathrm{~b}$ & & Moyenne & 10,16 & \\
\hline Moyenne & 10,16 & & Moyenne & 10,16 & & Ecart-type & 3,86 & \\
\hline $\begin{array}{l}\text { Ecart- } \\
\text { type }\end{array}$ & 3,86 & & Ecart-type & 3,86 & & C.V. (\%) & 37,99 & \\
\hline C.V. (\%) & 37,99 & & C.V. $(\%)$ & 37,99 & & & & \\
\hline
\end{tabular}

Tableau 5 : Liste des espèces d'adventices identifiées, selon les fréquences décroissantes, dans les cultures de menthe.

\begin{tabular}{|c|c|c|c|c|}
\hline Espèces & Familles & $\begin{array}{l}\text { Noms communs } \\
\text { et locaux }\end{array}$ & $\begin{array}{l}\text { Fréquences } \\
\text { absolues }\end{array}$ & $\begin{array}{l}\text { Fréquences } \\
\text { relatives }\end{array}$ \\
\hline Cyperus rotondus $\mathrm{L}$. & Cyperaceae & Souchet rond & 9 & 11,69 \\
\hline Heliotropium indicum $\mathrm{L}$. & Boraginaceae & Herbe à papillons & 9 & 11,69 \\
\hline Phyllantus amarus Schum. \& Thonn. & Euphorbiaceae & Phyllantus & 9 & 11,69 \\
\hline Euphorbia hirta L. & Euphorbiaceae & - & 8 & 10,39 \\
\hline Portulaca oleracea $\mathrm{L}$. & Portulacaceae & Pourpier & 7 & 9,09 \\
\hline Cleome ciliata Shum. et Thonn. & Capparaceae & - & 6 & 7,79 \\
\hline Amaranthus spinosus L. & Amaranthaceae & $\begin{array}{l}\text { Amarante } \\
\text { épineuse }\end{array}$ & 4 & 5,19 \\
\hline Euphorbia hyssopifolia L. & Euphorbiaceae & - & 4 & 5,19 \\
\hline Euphorbia prostata Aiton & Euphorbiaceae & Euphorbe prostrée & 4 & 5,19 \\
\hline Eclipta prostrata (L.) L. & Asteraceae & Moussofih & 3 & 3,90 \\
\hline $\begin{array}{l}\text { Eragrostis tenela (L.) Roemer \& } \\
\text { Schultes }\end{array}$ & Poaceae & - & 3 & 3,90 \\
\hline
\end{tabular}


Panicum repens $\mathrm{L}$.

Paoceae

Pentodon pentandrus (Schum. \&

Thonn.) Vatke

Rubiaceae

\section{DISCUSSION}

Les deux espèces de menthes sont produites par les maraîchers d'Abidjan au cours de toute l'année. Dans la commune de Koumassi, certains maraîchers se contentent de ces deux espèces de menthes car les principales espèces exploitées notamment la laitue (Lactuca sativa L. (Asteraceae) et le chou (Brassica oleracea L. (Brassicaceae) sont détruites par la volaille essentiellement composée par les poulets des concessions avoisinantes qui sont friands de leurs feuilles coriaces. Cette situation serait liée à la forte urbanisation de la commune selon le maraîcher rencontré. Selon Butler et Spencer (2010) cité par SAMBIENI et al. (2018), les territoires périurbains constituent les espaces qui recevront la forte urbanisation annoncée en Afrique

Selon Douay (2008), la menthe verte (Mentha spicata) est retrouvée essentiellement sur les terrains riches, profonds et frais; elle n'aime pas les sols calcaires; elle est retrouvée surtout en basse altitude dans les régions tempérées entre 400 et $1800 \mathrm{~m}$ et préfère les lieux ensoleillés à semi ombragés. Quant à la menthe poivrée (Mentha piperita), issue de l'hybridation spontanée entre la menthe aquatique et la menthe verte, elle se cultive au printemps ou à l'automne suivant les régions, apprécie un sol fertile et frais, se développe préférentiellement dans un endroit ensoleillé et un sol drainé (Abbes, 2014).

En plus du mode de propagation asexué des menthes par boutures appliqué dans cette étude, Sébastien (2008) signale la méthode de reproduction sexuée pour les espèces de menthes produisant des graines telles que la menthe verte; ce qui n'est pas le cas de la menthe poivrée qui fleurit mais ne produit pas de graines (CNRA, 2015).

La présence d'autres espèces de culture au sein de la culture principale de menthe pourrait se justifier par le fait que ces dernières peuvent procurer au maraîcher des revenus substantiels à court ou moyen terme dans l'attente de la récolte de la culture principale et d'autres part elles assurent des revenus plus ou moins permanents au maraîcher. En effet, les récoltes de ces plantes associées sont vendues, de façon permanente aux petits clients en détail pour leurs besoins immédiats et parfois à des vendeuses grossistes de plantes légumières qui les proposent aux vendeuses détaillantes. Cependant, il n'est pas exclu que ces espèces soient exploitées comme cultures principales sur des planches entières. Dans ce cas, les détaillants ne sont plus servis pour l'espèce concernée car en tant que culture principale, la récolte sera vendue aux grossistes par planche. Les caractéristiques et la qualité nutritive de certains légumes ont été abordés par des auteurs selon les régions (Fondio et al., 2013 ; Oulai et al., 2014 ; Ngo Bogmis et al., 2018).

Le nombre d'espèces de culture inventoriées qui est de 28 espèces, est inférieur à celui de 40 espèces de cultures maraîchères rapporté pour la Côte d'Ivoire (CNRA, 2015). Cette différence pourrait due au fait que l'étude s'est déroulée sur le site d'un seul maraîcher qui est aussi confronté la proximité des concessions d'où provient la volaille qui s'attaquent à certaines espèces de culture.

La flore des adventices composée de 18 espèces dans cette étude est peu riche comparativement à celles des adventices de Mangara et al. (2010) qui est de 239 espèces dans les champs d'ananas, de Traoré (2007) qui est de 259 espèces par dans les palmeraies au Sud de la Côte d'Ivoire, en zone forestière et de Boraud (2000) avec 234 espèces inventoriées en culture de canne à sucre, dans le domaine soudanais au Nord de la Côte 
d'Ivoire et Ipou Ipou (2005) avec 284 espèces au Nord du pays en culture de cotonnier. La différence entre ces différentes flores pourrait s'expliquer par la durée entre les interventions de désherbage qui varie selon les cultures. En effet, dans la culture de menthes comme pour la majorité des cultures maraîchères, les planches sont régulièrement binées (chaque semaine) pour éviter le tassement du sol et faciliter l'infiltration de l'eau d'arrosage. Ces opérations ne facilitent pas l'installation des mauvaises herbes. Dans le cas des cultures annuelles ou pluriannuelles les périodes de désherbage sont plus espacées (au moins 3 moins), ce qui favorise le développement des adventices. L'étendue des exploitations pourrait également justifier la différence des périodes d'intervention du désherbage. En effet, les parcelles de maraîchères sont de taille moindre, ce qui permet au maraîcher de les parcourir quotidiennement. Sans ces activités qui contribuent énormément à l'élimination des mauvaises herbes, l'on assisterait aussi à leur développement en abondance. C'est pourquoi, selon Korichi (2007), il n'existe pas de flore adventice spécifique à une culture donnée, mais plutôt à des paramètres écologiques et des facteurs agricoles.

Les espèces adventices herbes rencontrées appartiennent aux familles des Euphorbiaceae et des Poaceae qui prédominent et à moindre degré à celles des Ceasalpiniaceae et les Portulacaeae. La présence régulière de certaines de ces espèces serait liée au fait qu'elles sont utilisées pour des soins et se retrouvent parfois protégées sur certaines parcelles. L'influence des stades de développement des menthes sur la flore adventice pourrait se justifier par les interventions de désherbage. C'est le cas de Eclipta prostrata et Heliotropium indicum. Phyllantus amarus a été recensé par Sylla et al. (2018) comme une plante antipaludique. Talinum triangulare exploitée ici comme une espèce légumière, a été inventoriée comme une espèce d'adventice à grande amplitude écologique et qualifiées d'ubiquistes par Mangara et al. (2010).

\section{Conclusion}

Globalement, l'étude a permis d'inventorier 46 espèces constituant la flore du site de maraîchage étudié dans la Commune de Koumassi à Abidjan. Il ressort de cette étude que la culture principale, la menthe, est constituée de deux (2) espèces appartenant à la famille des Lamiaceae. Il s'agit de la menthe verte (Mentha spicata) et la menthe poivrée (Mentha piperita). En plus des espèces de menthe, 26 autres espèces de légumes sont exploitées sur le site d'étude, les mieux représentés étant Colocasia esculenta, Amaranthus hybridus et Cleome gynandra, Cleome gynandra, Cymbopogon citratus et Hibiscus sabdariffa. Les intérêts de ces plantes légumières résident en l'assurance de revenus substantiels et permanents à l'exploitant. L'ensemble de ces plantes légumières sont utilisés par l'homme pour les besoins alimentaires et les organes principalement utilisés sont les feuilles. Au sein de ces espèces utiles, 18 espèces d'adventices ont été identifiées. Toutefois, certaines espèces d'adventices sont utilisées aussi par l'homme comme plantes médicinales. Ces résultats montrent les possibilités locales d'associations culturales à base de la menthe et la présence d'une flore spontanée qui peut accompagner la culture des espèces de menthe sur un site en perpétuel remaniement. Les résultats obtenus indiquent une flore adventice dominée par Cyperus rotondus, Heliotropium indicum, Phyllantus amarus, Euphorbia hirta, Portulaca oleracea et qui subit un effet des stades de développement des menthes. De tels résultats donnent des informations sur la richesse et la composition de la flore in situ et peuvent orienter les actions à mener pour le contrôle des mauvaises herbes en culture de menthe.

\section{CONFLIT D'INTERETS}

Les auteurs de ce manuscrit déclarent qu'il n'y a aucun conflit d'intérêt entre eux.

\section{CONTRIBUTIONS DES AUTEURS}

Dans la présente étude, KS et BBK ont assuré l'élaboration du protocole de 
recherche, la collecte, le traitement des données et la rédaction du manuscrit. Ils ont été soutenus par FS et ADEA dans la relecture des différentes versions pour l'amélioration de la qualité scientifique du manuscrit.

\section{REMERCIEMENTS}

Les auteurs remercient Monsieur SORO Nalourou, le maraîcher qui a accepté de mettre à notre disposition sa parcelle de cultures maraîchère et tout le matériel technique pour l'exécution des travaux de terrain dans la commune de Koumassi sans oublier son implication personnelle dans le suivi des travaux.

\section{REFERENCES}

Abbes A. 2014. Evaluation de l'activité antioxydante des huiles essentielles d'Ammoides verticillata «noukha » de la Région de Tlemcen. Mémoire de Master, Faculté des Sciences de la Nature et de Vie et des Sciences de la Terre et de l'Univers, Département d'Agronomie et des Forêts, Université Abou Bekr Belkaid, Algérie, $63 \mathrm{p}$.

Adou Yao CY, Kpangui KB, Koffi BJC, Vroh BTA. 2015. Farming practices, diversity and utilizations of associated species of cocoa plantations in a forest savannah Center Côte d'Ivoire. Global Journal of Wood Science, Forestry and Wildlife, 3(3): $94 \mathrm{p}$.

Akesse EN, Ouali-N'goran S-WM, Tano Y. 2015. Insectes ravageurs du piment Capsicum chinense Jacq. (Solanaceae) à Port-Bouët (Abidjan - Côte d'Ivoire) : Pratiques de lutte par les pesticides chimiques. Journal of Applied Biosciences, 93 : 8667 - 8674.

Angaman DM, Barima YSS, Séguéna F, Kouassi AF, Soro K. 2001. Les plantes alimentaires vendues sur les marchés d'Abidjan. Exposé UV Bota (12. Ethnobotanique et Pharmacopée Africaine), Université de Cocody, UFR Biosciences, Laboratoire de Botanique In État des ressources phytogénétiques pour l'alimentation et l'agriculture : Second rapport national. Ministère de l'agriculture de la Côte d'Ivoire, p. 20. Atidegla SC, Agbossou EK, Huat J, Glele Kakai R. 2011. Contamination métallique des légumes des périmètres maraîchers urbains et péri urbains : Cas de la commune de Grand-Popo au Bénin. Int. J. Biol. Chem. Sci., 5(6): 2351-2361.

DOI: http://dx.doi.org/10.4314/ijbcs.v5i6.15

Benayad N. 2008. Les huiles essentielles extraites des plantes médicinales marocaines: moyen efficace de lutte contre les ravageurs des denrées alimentaires stockées. Projet de recherche, Université Mohammed VAgdal, Faculté des Sciences de Rabat, 61 p.

Boraud NKM. 2000. Etude floristique et phytoécologique des adventices des complexes sucriers de Ferké 1 et 2, de Borotou -Koro et de Zuénoula, en Côte d'Ivoire. Thèse de Doctorat 3è Cycle, UFR Biosciences, Université d'AbidjanCocody, 157p.

Belhadi A, Mehenni M, Reguieg L, Yakhlef H. 2016. Pratiques phytosanitaires des serristes maraichers de trois localités de l'est des Ziban et leur impact potentiel sur la sante humaine et l'environnement. Revue Agriculture, (1) : 09-16

CNRA. 2015. Agriculture Ivoirienne : Culture des maraîchères. CNRA-Abidjan, 1p. info@agriculteurivoirien.org

Doumbia M, Kwadjo KE. 2009. Pratiques d'utilisation et de gestion des pesticides par les maraîchers en Côte d'Ivoire : Cas de la ville d'Abidjan et deux de ses banlieues (Dabou et Anyama). Journal of Applied Biosciences, 18: 992-1002.

Fondio L, Agbo AE, Mahyao A, N'zi JC, N'gbesso Mako FDP, Djidji AH, Kouame C. 2013. Quelles contributions des légumes feuilles traditionnels à la sécurité alimentaire et à l'allègement de la pauvreté des populations urbaines en Côte d'Ivoire ? Conférence AGRAR 2013 « L'agriculture face aux défis de l'alimentation et de la nutrition en Afrique : Quels apports de la recherche 
en zones cotonnière ». Du 3-7 juin 2013, Yamoussoukro-Côte d'Ivoire, 13p.

Fondio L, Agbo AE, Mahyao A, N'zi JC, Tahouo O. 2011. L'importance socioéconomique des légumes-feuilles pour la population des villes de Côte d'Ivoire, CNRA, 8-9.

Hammami S, Abdesselem M. 2005. Extraction et analyse des huiles essentielles de la menthe poivrée de la région de Ouargla. Thèse Ing Université Blida, Algérie, $69 \mathrm{p}$.

Ipou Ipou J. 2005. Biologie et écologie de Euphorbia heterophylla L. (Euphorbiaceae) en culture cotonnière, au Nord de la Côte d'Ivoire. Thèse de Doctorat, Université de Cocody, Abidjan, $200 \mathrm{p}$.

Korichi S. 2007. Etude du comportement de la menthe poivrée Mentha peperita $\mathrm{L}$. sous palmeraies dans la Région de Ouargla. Mémoire de fin d'études, Diplôme d'Ingénieur d'Etat en Sciences Biologiques, Faculté des sciences et sciences de l'Ingénieur, Département des sciences biologiques, Universite Kasdi Merbah - Ouargla, Algérie, 86 p.

Mangara A, N'da AAA, Traoré K, Kéhé M, Soro K, TOURE M. 2010. Etude phytoécologique des adventices en cultures d'ananas (Ananas comosus (L.) Merr.) dans les localités de Bonoua et N'douci en Basse Côte d'Ivoire. Journal of Applied Biosciences, 36: 2367-2382.

Ngo Bogmis Mn, Ngwa Fa, Manga GA. 2018. Evaluation nutritionnelle de la morelle africaine au Cameroun. Int. J. Biol. Chem. Sci., 12(1): 62-74. DOI: https://dx.doi.org/10.4314/ijbcs.v12i1.5

Oulai P, Lessoy Zoue RM, Megnanou R, Doue S. 2014. Proximate composition and nutritive value of leafy vegetables consumed in northern Côte d'Ivoire. European Scientific Journal, 10(6): 212227.

Sambieni Kr, Bilosso Moyene A, Occhiuto R, Sambieni E, Natta Ak, Bogaert J. 2018. La biodiversité des parcelles habitées en zone périurbaine à Kinshasa : déterminants socio-biophysiques et représentations. Int. J. Biol. Chem. Sci., 12(3): $1164-1183 . \quad$ DOI: https://dx.doi.org/10.4314/ijbcs.v12i3.8

Sangaré A, Koffi E, Akamou F, Fall C. 2009. Etat des ressources phytogénétiques pour l'alimentation et agriculture : second rapport national : rapport national sur l'état des ressources phytogénétiques pour l'alimentation et l'agriculture. 15: p.12, p.64.

Sylla Y, Silue Dk, Ouattara K, Kone MW. 2018. Etude ethnobotanique des plantes utilisées contre le paludisme par les tradithérapeutes et herboristes dans le district d'Abidjan (Côte d'Ivoire). Int. J. Biol. Chem. Sci., 12(3): 1380-1400. DOI: https://dx.doi.org/10.4314/ijbcs.v12i3.25

Ton P. 2000. Intoxications et morts au Bénin par l'endosulfan. Pesticides et Alternatives, 10 : 2-5.

Traoré K. 2007. Etude comparée de la flore adventice des agro-écosystèmes élaeicoles (Elaeis guineensis Jacq.) en basse Côte d'Ivoire : Cas des localités de La Mé et de Dabou. Thèse de Doctorat, Université de Cocody, Abidjan, 161 p. 